\title{
BACHILLERATOS POPULARES EN ARGENTINA EDUCACIÓN DESDE LOS MOVIMIENTOS SOCIALES
}

\section{Juan Wahren}

\section{Resumen}

Los bachilleratos populares son experiencias de educación popular desplegadas desde diversos movimientos sociales que crean escuelas secundarias populares y autogestionadas para jóvenes y adultos. Estas experiencias se insertan en diversos territorios - barrios populares, sindicatos, fábricas recuperadas - con el objetivo de resistir las reformas escolares neoliberales, al tiempo que construyen alternativas educativas que apuntan al cambio social. La metodología utilizada para este trabajo se basó en entrevistas en profundidad a diversos integrantes de las experiencias, observaciones participantes y un relevamiento cuantitativo de los bachilleratos populares de todo el país realizado en el año 2016, lo cual permitió hacer un balance analítico de estas experiencias que cumplen quince años de existencia.

Palabras clave: educación popular, movimientos sociales, territorio, protesta social.

\begin{abstract}
Bachilleratos populares in Argentina. Education from social movements

The bachilleratos populares are popular education experiences self-management by social movements aimed at young and adult people to finish high school. These experiences growing up in diverse territories like popular neighborhoods, trade unions and factories recovered by their own workers with de aim to resist new liberalism in the system education and to build educational alternatives and social change. The methodology used in this article is based on the mixed methods qualitative and quantitative research tools like interviews and surveys to analyze these experiences that are fifteen years old.
\end{abstract}

Keywords: popular education, social movements, territory, social protest.

\footnotetext{
Juan Wahren: Sociólogo, magíster en Investigación en Ciencias Sociales y doctor en Ciencias Sociales por la Facultad de Ciencias Sociales de la Universidad de Buenos Aires (UBA). Investigador asistente del Consejo Nacional de Investigaciones Científicas y Técnicas (CONICET) en el Instituto de Investigaciones Gino Germani. Coordinador del Grupo de Estudios Rurales y del Grupo de Estudios sobre Movimientos Sociales de América Latina. Integrante del Grupo de Estudios sobre Movimientos Sociales y Educación Popular. Profesor adjunto del Seminario de Investigación Educación Popular y Movimientos Sociales (UBA). ORCID iD: 0000-0001-5594-0831

E-mail: juanwahren@gmail.com
} 


\section{Introducción. El contexto de surgimiento de los bachilleratos populares ${ }^{1}$}

En las últimas décadas, la Argentina fue parte de distintos procesos históricos que marcaron y reconfiguraron a los movimientos sociales (MS). Por un lado, la última dictadura militar eliminó físicamente a una generación de dirigentes y militantes populares, y estimuló la apertura de los mercados financieros y el desmantelamiento de gran parte del andamiaje productivo. Por otra parte, los diferentes gobiernos democráticos, principalmente el menemismo de la década del noventa y su continuidad en el gobierno de la Alianza con De la Rúa, impusieron reformas estructurales de corte neoliberal que cambiaron radicalmente el modelo económico y social del país (Zibechi, 2003; Svampa, 2008), así como el sistema educativo en su conjunto y, dentro de este, uno de los componentes que más sufrió fue la educación de jóvenes y adultos (EDJA). El cierre de la Dirección Nacional del Adulto durante estos años - hasta entonces organismo responsable del área en el ámbito nacionalconstituye una clara manifestación de ello.

Dentro de este marco, los movimientos sociales desplegaron sus acciones de resistencia, propuestas y prácticas alternativas tendientes a la construcción de "poder popular" y "cambio social". Así, (re)emergieron nuevos y viejos movimientos sociales: fábricas recuperadas, movimientos de trabajadores desocupados, movimientos juveniles y estudiantiles, centros culturales, sindicatos combativos y también pueblos indígenas y organizaciones campesinas, entre otros actores urbanos y rurales. Cada uno de estos movimientos, con sus particularidades, comenzó no solo a resistir, sino también a ensayar respuestas alternativas a estas reformas neoliberales. Comenzaron a organizarse de forma horizontal y asamblearia, a construir sus propios espacios de socialización política basados en la autonomía y la acción directa (Zibechi, 2003; Svampa, 2008).

Desde fines de la década del noventa hasta 2003 Argentina vivió un período de inestabilidad económica e institucional — con las rebeliones de diciembre de 2001 como momento cúlmine de esta crisis política y económica - $\mathrm{y}$, con la llegada del kirchnerismo, se inició una paulatina recomposición de la legitimidad de las instituciones hegemónicas, así como cierta estabilidad y crecimiento económico (Svampa, 2008). Así, la tensión

1 Este artículo retoma y actualiza los siguientes trabajos: Brickman, Chirom y Wahren, 2012; Aguiló y Wahren, 2014; y Longa, Stratta y Wahren, 2014. 
entre la autonomía de los movimientos sociales y la heteronomía estatal será uno de los clivajes principales para comprender la acción colectiva de estas experiencias.

En este contexto de mayor intervención estatal y cierto reflujo de las capacidades de movilización de los movimientos sociales, en 2004 nacieron las primeras experiencias de los bachilleratos populares (BP), en el marco de organizaciones que venían protagonizando las acciones colectivas de resistencia y las prácticas alternativas.

La emergencia de los BP no puede entenderse escindida de las distintas experiencias educativas construidas desde los movimientos sociales que aparecen en diversos países de América Latina y Argentina, enmarcadas en los procesos de construcción de alternativas políticas (Zibechi, 2005; Sverdlick, 2008; Torres Carrillo, 2017) por parte de esas organizaciones sociales.

Según un relevamiento realizado en el año 2015 por el Grupo de Estudios sobre Movimientos Sociales y Educación Popular de la Universidad de Buenos Aires (GEMSEP, 2015) hay alrededor de 90 bachilleratos populares en todo el país, en su gran mayoría localizados en la ciudad de Buenos Aires (34) y el Gran Buenos Aires (53). Existen también experiencias en las provincias de Buenos Aires (Mar del Plata, Pergamino y Luján), en Mendoza, Santa Fe, Río Negro y Jujuy.

Caracterizamos a los BP como escuelas públicas, populares y autónomas cuyas principales demandas son la obtención de títulos oficiales, el financiamiento integral y el reconocimiento de su especificidad por parte del Estado, sin que ello, como veremos, implique la pérdida de la autonomía política y pedagógica de dichas experiencias (Ampudia y Elisalde, 2015; López Fittipaldi, 2016; Blaustein Kappelmacher, Rubinsztain y Said, 2018).

La metodología utilizada para este trabajo se basó en entrevistas en profundidad a diversos integrantes de las experiencias, observaciones participantes y un relevamiento cuantitativo de los BP de todo el país realizado desde el equipo de investigación al que pertenezco (GEMSEP, 2016), todo lo cual permitió realizar un balance analítico de estas experiencias, que cumplen quince años de existencia.

Las entrevistas en profundidad fueron realizadas en el marco de los proyectos de investigación del GEMSEP entre los años 2009 y 2014, y abarcaron 30 entrevistados, la mayor parte de ellos educadores de 10 BP diferentes pertenecientes a los tres principales espacios de articulación que tienen estas experiencias: la Coordinadora de Bachilleratos Populares en Lucha (CBPL), la Red de Bachilleratos Populares (RBP) y la Coordinadora por la Batalla Educativa (CBE). Estas entrevistas se complementaron con las declaraciones de diferentes educadores recolectadas en un debate público organizado por el GEMSEP en el año 2014, al cumplirse diez años de las experiencias de los BP, que fue editado en forma de cuadernillo (GEMSEP, 2015). Asimismo, se realizaron observaciones participantes a partir de la propia experiencia de 
participación en la creación y acompañamiento de estas escuelas populares desde 2004 hasta 2016, tanto en diferentes BP como en los tres espacios de articulación de estos. También se participó del relevamiento nacional de BP realizado como parte del colectivo de investigación del GEMSEP (2016). Finalmente, se realizaron comunicaciones personales con un referente de cada espacio de articulación (tres en total) durante el año 2019, a fin de actualizar algunos de los datos obtenidos durante las entrevistas, el relevamiento y las observaciones. Los nombres de los entrevistados han sido cambiados para mantener su anonimato, dejando solamente la referencia al BP y al espacio de articulación al que pertenecen. Por falta de espacio muchos de los testimonios de los entrevistados no fueron incorporados en el texto del presente artículo.

Este entramado de entrevistas y observaciones, y el relevamiento general de estas experiencias permitieron reconstruir las acciones colectivas de este movimiento social desde sus orígenes hasta la actualidad, dando cuenta de las diferentes fases que atravesaron estas experiencias educativas, tanto en su organización y articulación como en sus procesos de territorialización y relación (en tensión) con el Estado en sus diferentes niveles. Los datos fueron analizados desde diversas dimensiones, que fueron los clivajes de la reconstrucción de las diferentes fases: a) procesos organizativos internos de cada BP y de los procesos de articulación; b) tensiones, debates y rupturas de los procesos de articulación; c) procesos de territorialización de los BP en los barrios populares, sindicatos y fábricas recuperadas; d) dinámicas políticopedagógicas de las experiencias, e) relaciones en tensión con el Estado en sus diferentes niveles (nacional, provincial, local), así como con las instancias de control o regulación directos sobre las experiencias del sistema escolar formal (inspectores, Secretaría de Asuntos Docentes, etcétera).

Por último, cabe resaltar que quien escribe fue parte de estas experiencias desde sus comienzos en 2004 (y durante los pasos previos) hasta el año 2016. A la vez, también participa en el GEMSEP, desde su conformación en 2008, donde se realizan investigaciones acerca de los BP desde las propias experiencias $^{2}$ (Alcántara, 2016). Esto implica que parte de la reconstrucción analítica de la experiencia de los BP proviene de la propia experiencia militante (el "estar allí") y de la autorreflexividad de la acción de los movimientos sociales en cuestión, articuladas con los saberes y las técnicas de investigación académicas. Desde ese lugar, situado en y desde los BP, pero también desde la investigación académica, es que se construye el presente trabajo, que intenta comprender los procesos organizativos y formativos de los BP, a la vez que presenta análisis críticos al devenir de estos movimientos sociales educativos.

2 En sus orígenes el equipo de investigación fue fundado por activistas de los BP que, a su vez, tenían algún tipo de adscripción académica, sea como estudiantes, docentes o investigadores en formación (Alcántara, 2016). 


\section{Las fases de la acción colectiva de los bachilleratos populares ${ }^{3}$}

En este apartado proponemos una periodización de las diferentes fases de la acción colectiva de los BP, desde los momentos previos de la conformación de las primeras experiencias hasta la actualidad. Distinguimos cuatro fases diferenciadas que dan cuenta de los desafíos y debates que se presentan en cada coyuntura particular, las cuales se encuentran determinadas por una multiplicidad de variables: a) cambios organizativos que se producen en el interior de los BP y sus instancias de articulación; b) cambios estructurales en las políticas públicas con respecto a la EDJA, entendidos como "estructuras de oportunidades políticas" (Tarrow, 2009) que permiten ampliar, o no, la frontera normativa para el reconocimiento estatal de estas experiencias.

Asimismo, a lo largo de su proceso organizativo y de acción colectiva, los BP han tenido distintas fases de "visibilidad" y "latencia" (Melucci, 1994), así como momentos de negociación y conflicto dentro de las organizaciones y con respecto al Estado en sus distintos niveles (nacional, provincial y municipal/local). A partir del año 2004, en el marco del reflujo del "ciclo de protesta" (Tarrow, 2009) de resistencia al neoliberalismo y a pocos años de las "rebeliones" de 2001 y 2002, (re)emergen diferentes experiencias de educación popular de diversos movimientos sociales.

\section{Los pasos previos y los primeros bachilleratos populares: 2002-2004}

Como antecedente de la conformación de los BP se puede retomar un espacio de coordinación - que duró poco más de un año- en torno a la educación popular, que surgió al calor de los debates suscitados luego de las rebeliones de 2001 y 2002. Este espacio organizó algunos encuentros y actividades para la discusión y la formación de militantes y educadores en la perspectiva de la educación popular freireana (Freire, 1985). Para ello, las organizaciones que conformaron este espacio —-Barrios de Pie, ${ }^{4}$ la Organización Popular Fogoneros $(\mathrm{OPF})^{5}$ y la Cooperativa de Educadores e Investigadores Popu-

3 La reconstrucción histórica de las distintas fases de la acción colectiva de los BP se basa en las entrevistas y comunicaciones personales, así como en las observaciones realizadas entre 2004 y 2019.

4 Barrios de Pie es la organización territorial de Libres del Sur, en ese entonces Corriente Patria Libre, que luego del año 2003 asumió una postura de apoyo al kirchnerismo hasta pasar a la oposición a partir de fines de 2008. En 2019, luego de una ruptura, una parte de esa organización retomó su pertenencia al kirchnerismo y es parte del gobierno de Alberto Fernández, mientras que otra fracción se sumó al Peronismo Federal de Roberto Lavagna.

5 Esta organización - que tomó el nombre de Organización Popular Fogoneros recién en el año 2004- era conocida hasta entonces como "La Escuelita - Centro Cultural y Educativo Las Tunas", en referencia al barrio donde desarrollaba su trabajo territorial desde 1996. Desde 2016, en confluencia con otras organizaciones barriales del conurbano norte, conformaron el Frente Arde Rojo (FAR) dentro de Marabunta como espacio de articulación. 
lares (CEIP) ${ }^{6}$ - realizaron una serie de talleres y debates en universidades, barrios y fábricas recuperadas por sus trabajadores. De este proceso, surgió la iniciativa impulsada por la CEIP y replicada simultáneamente por la OPF de crear BP de jóvenes y adultos a partir de las necesidades concretas de los barrios populares y las fábricas recuperadas en las que la OPF y la CEIP, respectivamente, tenían trabajos previos. Así, los dos primeros BP se crean en el año 2004: el BP IMPA en la fábrica recuperada del mismo nombre en Capital Federal, impulsado por la CEIP junto con el Movimiento Nacional de Empresas Recuperadas (MNER), y el Bachillerato Popular Simón Rodríguez (BPSR), en el barrio Las Tunas, de Tigre, en el marco de la OPF.

"Los BP no surgen de la nada, sino como expresión de un montón de experiencias político-territoriales, sindicales que teníamos una militancia de resistencia pero también buscamos formas creativas de ejercer, hacer y decir la política de otra manera [...] en ese doble juego de la resistencia y la posibilidad de buscar nuevas formas se cristaliza como una experiencia de educación popular muy potente la de los BP, también porque todo el período de los treinta años anteriores había dejado como saldo un nivel de jóvenes y adultos, una población muy grande, que no había terminado sus estudios $[\ldots]$ esto podría dar a pensar que la experiencia de los BP viene a responder solamente a esa necesidad pero, a la vez que responde a esa necesidad, nosotros vemos que existe en los 'bachis' una nueva forma de hacer política, que responde a una necesidad subjetiva, militante, de transformar la realidad, no en términos de cubrir parches, sino en términos de proponer nuevas maneras de educarnos, pensar y transformar el mundo." (Entrevista a Marcos, educador BPSR-CBPL, 2013).

De este modo, es posible considerar que la intencionalidad inicial de estas experiencias puede analizarse desde dos sentidos complementarios. Por un lado, la terminalidad secundaria para el sujeto joven y adulto era una demanda importante en los territorios donde actuaban estas organizaciones y donde el Estado no ofrecía espacios factibles para contener estas necesidades educativas. Por otro lado, las organizaciones impulsoras planteaban el desafío de construir espacios educativos autogestionados con formatos educativos alternativos y contrahegemónicos que tomaran distancia del formato estatal hegemónico y con un horizonte emancipatorio (Wahren y Aguiló, 2014; Ampudia y Elisalde, 2015).

6 La CEIP está conformada por un colectivo de docentes, investigadores y estudiantes universitarios que han propulsado actividades y experiencias de educación popular, principalmente en fábricas recuperadas y otros movimientos sociales. Luego de una ruptura en el año 2015 se conformaron dos espacios que siguieron impulsado diversos BP, la CEIP y la CEIP H (Histórica). 


\section{La conformación de la Coordinadora de Bachilleratos Populares en Lucha: 2005-200?}

A mediados del año 2005 se conformó el primer espacio de articulación de estas experiencias - denominado Interbachilleratos - con los primeros BP que se habían constituido hasta entonces. Los encuentros estaban orientados principalmente al intercambio y el debate de las experiencias pedagógicas, para fortalecer las distintas áreas educativas y conformar espacios de formación conjunta en educación popular. Con el tiempo, se fue incorporando un debate administrativo y de gestión de las experiencias educativas (por ese entonces, la acreditación de los títulos se hacía por medio del único bachillerato oficializado de Capital Federal - IMPA - y una escuela oficial de gestión privada de la provincia de Buenos Aires), al que se fueron sumando paulatinamente debates reivindicativos y políticos vinculados a las necesidades de obtener algún tipo de reconocimiento oficial para estas experiencias en lo que refiere a los títulos, el financiamiento, los salarios de los educadores y becas para los estudiantes.

"De la Interbachilleratos se arma la Coordinadora, y luego aparecen los otros espacios de articulación gremial en donde ingresan otras organizaciones sociales con otras trayectorias de militancia y otras concepciones políticas. Y obviamente ahí también hay un cambio en los bachilleratos populares. Aquel primer bachillerato popular Simón Rodríguez de Fogoneros y aquel primer bachillerato popular en IMPA no se llamaban 'bachillerato popular'. Se llamaban Bachillerato de Jóvenes y Adultos. No es un detalle, eso es parte de este proceso de construcción, que hace también a esas metamorfosis. Pero en esa metamorfosis hay una potencialidad de la experiencia que es el proyecto democrático radical, algunos hablan de 'proyecto comunitario' para graficar el desde abajo, otros 'proyectos autónomos'. A mí me gusta más la palabra autogestionarios”. (Azul, educadora BP IMPA, CEIP-CBPL, GEMSEP, 2015).

De esta manera, se puede observar cómo estos debates fueron transformando el carácter de los propios BP (incluso su autodenominación se fue politizando: pasaron de autodenominarse como "bachilleratos de jóvenes y adultos" a "bachilleratos populares") y del espacio de articulación al comenzar a realizarse diferentes acciones colectivas de protesta en torno a estas demandas básicas que se convirtieron en los acuerdos comunes del espacio.

Las primeras acciones colectivas de protesta consistieron en movilizaciones dirigidas a los distintos ministerios de Educación del ámbito nacional, provincial y de la ciudad de Buenos Aires. De este modo, se logró entablar una interlocución — no exenta de conflictos- con los funcionarios políticos de estos organismos. Sin embargo, el repertorio de acciones 
(Tarrow, 2009) se fue ampliando a medida que los "planes de lucha" se iban radicalizando para la obtención de las demandas por la oficialización de los títulos, las becas de los estudiantes, los salarios para los educadores y el financiamiento integral de las experiencias.

A las movilizaciones se sumaron clases públicas, cortes de calles, escraches a los ministros de Educación nacional y de la ciudad de Buenos Aires en la inauguración de la Feria del Libro, entre otras acciones de protesta, algunas de las cuales lograron una importante repercusión en los medios de comunicación y en el conjunto del campo educativo, transformando a los BP y su espacio articulador en un actor reconocido y con sus particularidades.

En el marco de estas acciones colectivas se conformó la CBPL, que resignificó el espacio de Interbachilleratos, de la articulación políticopedagógica a una articulación de las luchas que permitiera potenciar la visibilidad de los BP. Por otra parte, el número de bachilleratos, si bien creció y fue importante, no superó los cinco bachilleratos nuevos por año (GEMSEP, 2016).

Esta fase se cerró con la obtención, a fines de 2007, del reconocimiento oficial de los BP de la provincia de Buenos Aires vía la gestión privada (Dirección Provincial de Educación de Gestión Privada - DIPREGEP-) y, en el verano de 2008, los bachilleratos de Capital Federal obtuvieron un reconocimiento similar bajo el área de Planeamiento Educativo del Ministerio de Educación porteño como Unidad de Gestión Educativa Experimental (UGEE).

\section{Oficialización y multiplicación de los bachilleratos populares: 2008-2011}

A partir de la oficialización es posible marcar el nacimiento de una nueva etapa de los BP en Buenos Aires, que se caracterizó por el crecimiento del "ciclo de protesta" (Tarrow, 2009) y por el surgimiento de numerosos nuevos BP.

Por un lado, la oficialización cambió la "estructura de oportunidades políticas" (Tarrow, 2009) para impulsar espacios de educación popular. Esto, que era algo impensado pocos años antes, abrió la puerta a que más movimientos sociales conformaran sus propios BP, teniendo como horizonte que estaban dadas las condiciones para su pronta oficialización.

A su vez, muchos movimientos sociales comenzaron a ver en la creación de los BP estrategias para potenciar sus trabajos en los territorios y acrecentar su legitimidad mediante un proyecto educativo propio. Mientras que en el primer período abrieron solo $3 \mathrm{BP}$ y en el segundo 9, en el tercero ya fueron 65 los nuevos BP (GEMSEP, 2016) que dieron pie a un crecimiento exponencial de las experiencias.

A partir de 2008 se acrecentaron también las medidas de protesta que protagonizaron los BP y se sumó con más fuerza el reclamo por el pago de salarios al programa de reivindicaciones. Asimismo, se acrecentó el debate interno en torno a la oficialización y la consiguiente tensión entre la autonomía 
de sus construcciones y la heteronomía que imprimió la estatalidad. En esta fase se obtuvo el pago de salarios a los docentes de los BP oficializados, al tiempo que se confirmó el cambio de convenios de gestión privada a estatal en el caso de la provincia de Buenos Aires.

Un primer debate se dio en referencia al kirchnerismo y planteó la discusión sobre si podía haber, o no, bachilleratos oficialistas dentro de la coordinadora (en ese momento el kirchnerismo gobernaba la provincia de Buenos Aires y el Estado a nivel nacional). El debate se centraba en la autonomía necesaria que debían tener, o no, los BP para poder llevar adelante sus acciones de protesta. Finalmente, este debate terminó en una ruptura a fines del año 2008, dando lugar así al surgimiento de nuevo espacio de articulación de BP con una orientación kirchnerista: la Coordinadora del Oeste. Hoy en día se denomina Batalla Educativa y nuclea a más de $40 \mathrm{BP}$ (GEMSEP, 2016).

La segunda disyuntiva en el seno de los BP de la CBPL surgió en 2009, en torno a los procesos de oficialización, el cobro de salarios docentes y la posibilidad de que esto cercenara la autonomía de los BP. Este debate culminó con una segunda ruptura, esta vez por parte de organizaciones territoriales: La Pulpería, el BP Bajo Flores y el Movimiento Popular La Dignidad crearon la Red de Bachilleratos Populares Comunitarios (RBPC).

"Las cuestiones burocráticas que el Estado impone para la oficialización de estos proyectos también constituyen una traba y una dificultad para pensar en la oficialización de estas experiencias, por eso nosotros como red decidimos no aceptar algunos de los condicionamientos de la institucionalización estatal para preservar nuestra autonomía." (Ernesto, educador BP Villa Soldati-MP La Dignidad-RBPC, GEMSEP, 2015).

Así, los BP que conformaron el nuevo espacio de articulación entendieron que las reglamentaciones impuestas por la oficialización y el subsidio podrían quitarles capacidad de decisión, al mismo tiempo que consumir energía militante en tareas burocráticas en detrimento del proyecto político-pedagógico de los BP.

\section{De la visibilidad a la latencia en los territorios: 2012-2019}

En el 2012 se comenzó a esbozar el nacimiento de una cuarta etapa para la historia de los BP a raíz de la iniciativa del Programa FinEs (Plan de Finalización de Estudios Primarios y Secundarios), vinculada a la educación de jóvenes y adultos. ${ }^{7} \mathrm{El}$ impulso de este programa de terminalidad secundaria

7 "El Plan FinEs, implementado en 20 provincias del país, persigue como objetivo garantizar la finalización de la escolaridad a jóvenes y adultos que no hayan iniciado o completado sus estudios" (GEMSEP, 2014, p. 68). 
masiva generó cierto desmedro presupuestario de los centros educativos de niveles secundarios (CENS) en general y en los CENS conveniados con BP en particular, ya que el Plan FinEs se reivindicó también como parte de la educación popular teniendo a Paulo Freire (1985) como uno de sus referentes pedagógicos principales, según sus documentos (GEMSEP, 2014). Con la expansión de los FinEs se comenzó a negar, por parte del Estado, el otorgamiento de nuevas oficializaciones a BP, con el argumento de que ahora había espacios estatales que solucionaban la carencia por la que habían surgido los propios BP. Cambiaban radicalmente las "estructuras de oportunidades políticas" (Tarrow, 2009) para continuar el crecimiento de los BP.

"En los BP hay un impacto de las políticas estatales a nivel provincial, principalmente con el plan FinEs en nuestro territorio, que en forma extendida han empezado a surgir estas experiencias y que en nuestro caso coincidió con un momento de crisis interna del bachillerato muy fuerte, que hizo que el año pasado hubiera una crisis de legitimidad del proyecto del bachillerato en el territorio y que impactara fuertemente en el colectivo docente, no solo en los estudiantes. Esto nosotros, como militantes, intentamos pensarlo críticamente." (Entrevista a Lila, educadora BP Roca Negra, BPRC-CBPL, 2013).

El avance de este plan gubernamental generó, entonces, un fuerte debate en el seno de los diferentes BP sobre aceptar o no la posibilidad de ser oficializados bajo la modalidad del FinEs, pues una mayoría de los BP caracterizó como una experiencia regresiva al FinEs respecto al CENS, ya que se los consideraba como espacios que precarizaban la educación y la calidad pedagógica, a la vez que precarizaban laboralmente a los docentes que allí trabajaban. Otros BP comenzaron a verlos como una opción para obtener cierto reconocimiento oficial para los títulos y salarios docentes. En efecto,

“[...] los debates acerca de cómo los BP pueden coexistir con los FinEs en el territorio cobran centralidad, y la caracterización de conjunto parece señalar que la relación que predomina entre ellos es de conflicto y competencia por la matrícula, aunque con niveles de intensidad dispares en distintos territorios." (Blaustein Kappelmacher, Rubinsztain y Said, 2018, p. 134).

"Los FinEs, si bien son un programa supuestamente único, en su aplicación después depende el uso de la correlación de fuerzas y la particularidad de cada territorio, de cada municipio. Y en esas experiencias nosotros en estos años hemos encontrado muchos compañeros trabajando en un sentido similar al del FinEs. Incluso hay algún bachillerato que en este momento quedó afuera de la negociación por el reconocimiento y está otorgando títulos vía FinEs sin cambiar nada del régimen de cursada que tiene el bachillerato, ni en 
reconocimiento de sus particularidades." (Gonzalo, educador BP Rodolfo Walsh-CBE, GEMSEP, 2015).

Durante esta etapa, diversos BP lograron su reconocimiento oficial vía FinEs, algunos pocos como escuela de adultos y hay una gran mayoría que aún continúa sus actividades sin ningún reconocimiento oficial. Esto provocó cierta ralentización en la apertura de nuevos BP, que también fue notable en la menor cantidad de acciones de protesta, y, así, el sostenimiento de cada "plan de lucha" de los distintos espacios de articulación de los BP se hizo más dificultoso que en la etapa anterior. Paralelamente, a partir del año 2016 parte de las movilizaciones se fue orientando hacia la confluencia con otros actores del campo educativo que se oponían a las reformas del gobierno de Mauricio Macri a escala nacional y también en la provincia de Buenos Aires y la ciudad de Buenos Aires, donde se congelaron, entre 2016 y 2018, los reconocimientos de nuevos BP. En este sentido, "se intensifica la participación de muchas organizaciones que forman parte de la CBPL en movilizaciones vinculadas con la defensa de la educación pública estatal, ante el carácter regresivo de las políticas implementadas en este período" (Blaustein Kappelmacher, Rubinsztain y Said, 2018, p.135).

Al mismo tiempo, se profundizó la relación de algunos de los BP de los distintos espacios de articulación con las herramientas gremiales de los trabajadores de la educación, tal como afirman Blaustein Kappelmacher, Rubinsztain y Said. Pese a que en los comienzos hubo relaciones tirantes entre los sindicatos docentes y los BP, esto se fue rearticulando y ya a partir de 2012 "distintas organizaciones impulsoras de BP comienzan a habitar activamente e, incluso, a participar en el armado de herramientas sindicales" (2018, p. 135).

En este período también se elaboró una serie de iniciativas legislativas que permitirían el reconocimiento integral de las experiencias de los BP, en efecto,

“[...] se ensayan iniciativas desde el ámbito legislativo, tratando de avanzar en su reglamentación, y algunas organizaciones de la CBPL, junto con la RBPC, participan en la elaboración de diversos proyectos de ley tanto en la ciudad de Buenos Aires como a nivel nacional." (Blaustein Kappelmacher, Rubinsztain y Said, 2018, p. 135).

Estos proyectos, si bien lograron debatirse en las comisiones legislativas, no lograron llegar al debate general de las legislaturas provinciales ni del Congreso Nacional.

En concreto, durante este período la CBPL comenzó un proceso de cierto estancamiento con una menor cantidad de planes de lucha y agendas cada vez más escindidas entre los BP de la ciudad y los de la provincia de Buenos Aires. Asimismo, muchos BP fueron dejando de participar de las reuniones 
mensuales y las movilizaciones, no por una ruptura política, sino por falta de dinamismo del espacio; incluso las negociaciones con los funcionarios políticos dejaron de tener, durante algunos momentos de esta etapa, una centralidad en la coordinadora y algunos BP negociaron individualmente con funcionarios de ambos distritos, lo cual generó algunos conflictos internos y reajustes en la CBPL. ${ }^{8}$

Por su parte, la RBPC se rearticuló y se fortalecieron los BP pertenecientes al MP La Dignidad con la incorporación al movimiento de algunos de los BP que eran hasta entonces independientes, pero al mismo tiempo otros BP dejaron ese espacio de coordinación (retornaron a la CBPL o continuaron sin articularse con otros BP), que hoy en día nuclea a cinco BP del MP La Dignidad. Sus participaciones en las movilizaciones fueron cada vez más escasas y reapareció nuevamente el debate en torno al cobro o no de los salarios docentes, también en correlación con otros debates sobre el corrimiento político del MP La Dignidad hacia posiciones de mayor articulación con el Estado y con la política institucional y cercanía al espacio kirchnerista a partir del año $2018 .{ }^{9}$

Por otro lado, la Coordinadora por la Batalla Educativa fue la que asumió con mayor profundidad su articulación con el Plan FinEs, por lo que muchos de sus BP fueron reconocidos en esa modalidad. Dejaron de participar de las movilizaciones de los $\mathrm{BP}$ y se debilitaron los espacios de negociación con los funcionarios de la provincia de Buenos Aires, donde se ubican todas sus experiencias. Al igual que la RBPC, fueron fusionándose todos los BP en torno a una sola organización territorial-gremial anclada principalmente en el Sindicato de Canillitas y en la Confederación General del Trabajo (CGT), la principal central sindical del país. Los BP que no se fusionaron salieron del espacio de coordinación y quedaron sin espacios de articulación específica. ${ }^{10}$

Para finalizar esta fase, cabe destacar que, a quince años de su conformación, las experiencias siguen vigentes hasta el presente, en un período que podríamos caracterizar como de "latencia" (Melucci, 1994), en el que los BP se van reificando, tanto en términos identitarios como políticopedagógicos, pero se mantienen aún como la experiencia contemporánea de educación popular impulsada por movimientos sociales más importante y sostenida en el tiempo en Argentina.

8 Esta actualización se basa en una comunicación personal con Ricardo, referente de la CBPL, realizada en el año 2019.

9 Esta actualización se basa en una comunicación personal con Paula, referente de la RBPC, realizada en el año 2019.

10 Esta actualización se basa en una comunicación personal con Rubén, referente de la CBE, realizada en el año 2019. 


\section{Las acciones colectivas de protesta de los bachilleratos populares: entre la tensión y la negociación con el Estado}

En este apartado se analizan con mayor profundidad los procesos de acción colectiva y la relación de los BP con el Estado. De acuerdo con las relaciones de fuerza específicas de cada distrito y de los espacios en el andamiaje institucional que fueron encontrando o creando los BP, los niveles de reconocimiento estatal y los recursos simbólicos y económicos que obtuvieron en cada distrito fueron muy diferentes. Así, en la ciudad de Buenos Aires, la mayor parte de los BP tienen el reconocimiento estatal de sus títulos, una gran parte de estos cobran salarios docentes y becas estudiantiles, y reciben esporádicamente subsidios para la infraestructura de las escuelas populares y autónomas (GEMSEP, 2016; Alfieri y Lázaro, 2019a). En la provincia de Buenos Aires, la tasa de reconocimiento es bastante menor y la mayoría se encuentra aún sin ningún tipo de reconocimiento, solamente once BP tienen reconocimiento de títulos y sueldos docentes y otros pocos obtienen esto mismo como anexos de los bachilleratos ya oficializados como CENS (GEMSEP, 2016; Pagano, 2019).

"Estamos pensando cómo conseguir que se reconozcan las parejas pedagógicas, cómo lograr que se reconozca la orgánica de la escuela porque en nuestro caso no tenemos director, secretario, sino que nos organizamos en una estructura colectiva, pero el Estado nos reconoce una estructura escolar clásica, donde nos dan un secretario y un profesor por curso, entonces ¿cómo hacer para que se reconozca esa forma de organización diferente que tenemos?" (Germán, educador BP Alberto Chejolán, MOI-CTA-CBPL, GEMSEP, 2015).

Hasta ahora, en la mayoría de los casos de bachilleratos oficializados, lo que el Estado reconoce es, según la sistematización que pudimos realizar a partir de las entrevistas y el relevamiento del GEMSEP (2016): a) títulos oficiales; b) salarios de directivos y docentes (solamente un educador por curso y con título habilitante); c) becas para estudiantes (solamente en la ciudad de Buenos Aires); d) subsidios esporádicos para infraestructura escolar; e) elección de docentes y directivos por parte de los propios BP.

\footnotetext{
"Nosotros mantenemos las cinco reivindicaciones históricas que son las que nos unen como organizaciones, que son: títulos oficiales para todos los estudiantes, salarios para todos los docentes porque nosotros nos entendemos como trabajadores de la educación y es desde ahí que llevamos a cabo nuestra tarea militante, becas para los estudiantes, financiamiento integral (infraestructura escolar y todo lo que implica los gastos de una escuela) y, por último, marcos normativos propios que contemplen las especificidades que tenemos." (Germán, educador BP Alberto Chejolán, MOI-CTA-CBPL, GEMSEP, 2015).
} 
Cabe resaltar que en ningún caso el Estado ha reconocido de manera integral la autonomía político-pedagógica de estas escuelas populares. Esto implicaría, según hemos podido reconstruir por medio de las entrevistas y las observaciones realizadas, el reconocimiento de las siguientes dimensiones (muchas de las cuales se aplican de hecho aunque el Estado no las reconozca): a) un currículo y didácticas propias; b) las pedagogías y didácticas de la educación popular; c) los equipos pedagógicos por curso con sus salarios correspondientes ("parejas pedagógicas"); d) el nombramiento de educadores populares más allá de su título habilitante; e) financiamiento regular e integral de las experiencias educativas (salarios para todos los educadores, infraestructura, becas, equipamiento, etcétera); f) las formas de validación pedagógica en los términos de las propias experiencias y su marco de acción territorial; g) un espacio colectivo de coordinación político-pedagógico que realiza las tareas que ordinariamente cumplen los equipos directivos de las escuelas tradicionales; h) las asambleas de estudiantes y docentes como espacio máximo de decisión de las escuelas populares autogestionadas.

Si bien estas experiencias han mantenido relaciones con diversos ámbitos estatales, la gestión de los recursos obtenidos y el proceso de construcción de las prácticas político-pedagógicas se han conformado de manera autónoma frente a cualquier estructura externa a la propia organización (Aguiló y Wahren, 2014; Odriozola, 2016; Pagano, 2019).

"Pensamos que nuestras experiencias de educación popular como BP, nuestras construcciones, conllevan una forma pensar lo público ligada a lo comunitario que sigue siendo público; son políticas públicas las que llevamos adelante día a día con nuestras experiencias, aunque no son políticas públicas estatales." (Paula, educadora BP Villa Crespo MPLDRBP, GEMSEP, 2015).

Como balance de estos quince años de experiencias de educación popular desde los BP, es posible afirmar que en general estos mantienen su autonomía político-pedagógica anclada en sus territorios, más allá de los procesos de oficialización (Palomeque, 2018), pues continúan definiendo colectivamente el nombramiento de docentes y equipos de coordinación, las formas de repartir los salarios — si es que los cobran (Grossi y Bergalio, 2019)—, las normas de convivencia, los contenidos curriculares, la gestión del espacio escolar mediante sus propias lógicas organizativas (Blaustein Kappelmacher, Rubinsztain y Said, 2018; Carnelli y Furfaro, 2015), reconfigurando, a la vez, lo que se considera como educación pública, que no es necesariamente estatal, sino educación pública, autónoma y popular. 
"El BPSR es una escuela que hace diez años se gestiona democráticamente, horizontalmente, en asambleas, sin directores, sin jerarquías, asumiendo distintas formas, pero siempre manteniendo ese principio políticopedagógico que da cuenta de que no es solo tapar un bache (que de última también lo es), sino con una determinada propuesta político-pedagógica que habla, para mí, de una radicalidad política distinta." (Entrevista a Marcos, educador BPSR-CBPL, 2013).

De este modo, entendiendo la autonomía como una forma de organización de un colectivo social que transforma radicalmente el sistema político dominante existente para constituir "un propio mundo según otras leyes" (Castoriadis, 2010), se puede afirmar que este horizonte aún se encuentra en construcción en los casos abordados. Estas experiencias habilitan la posibilidad para los movimientos sociales de desplegar sus prácticas en el territorio (Wahren y Aguiló, 2014) y de practicar la autonomía, al tiempo que atraviesan disputas concretas por esos territorios y por la construcción de una educación popular alternativa con otros actores del ámbito educativo (Chiaradia y Favre, 2019).

\section{Los bachilleratos populares en el territorio y sus prácticas político- pedagógicas}

Los BP ponen en práctica una serie de lineamientos político-pedagógicos anclados en el paradigma de la educación popular (García, 2018). Estos actúan como un horizonte de sentido que en la práctica no siempre se logra cristalizar en todo el proceso didáctico-pedagógico de la escuela. Sin embargo, se pueden esbozar, a partir de las entrevistas y observaciones realizadas, los siguientes lineamientos pedagógicos comunes a estas escuelas populares y autónomas: a) un proceso pedagógico dialógico entre educadores y educandos (diálogo de saberes diversos sin jerarquías entre ellos); b) la conformación de parejas o equipos pedagógicos docentes en cada asignatura o área educativa; c) el establecimiento de un currículo que combina la propuesta oficial con una propuesta pedagógica construida colectivamente desde cada BP; d) los lineamientos de convivencia construidos colectivamente entre docentes y estudiantes; e) las formas alternativas de evaluación cualitativa que se focalizan en los procesos educativos antes que en las notas cuantitativas que "miden" el aprendizaje de contenidos básicos; f) un enfoque pedagógico centrado en la perspectiva problematizadora de la realidad social con el objetivo de conformar estudiantes críticos; g) un enfoque pedagógico orientado hacia el cambio social; h) los espacios permanentes de (auto)formación en educación popular y de (auto) reflexión de las prácticas docentes y pedagógicas de los BP.

Estas son algunas de las prácticas político-pedagógicas que se pueden vislumbrar en la mayor parte de estas escuelas populares y autogestionadas 
(CEIP Histórica, 2016), prácticas que resignifican la subjetividad política e identitaria de los sujetos que participan de las experiencias de los BP y suponen también una interpelación al conjunto del campo educativo, al plantear diversas pedagogías populares y nuevas formas organizativas de lo escolar (Alfieri y Lázaro, 2019b).

Por otra parte, los procesos de "territorialización" de estas experiencias mediante los cuales los BP se involucran en la realidad y el contexto del territorio donde se insertan implican un complejo entramado de acciones y presentan una suerte de continuum territorial entre la escuela y el territorio circundante (Aguiló y Wahren, 2014).

En efecto, brindar una respuesta al vacío que en materia educativa dejaba el Estado en los sectores populares implicó una serie de conflictividades con el Estado y con las formas educativas hegemónicas (las cuales, por cierto, también se reproducen muchas veces dentro de los propios BP). Asimismo, el Estado plantea sus propias estrategias de territorialización, y, en este sentido, los planes FinEs son un claro ejemplo de disputa entre el Estado y los BP en lo institucional y en los propios territorios que, como vimos, tienen un fuerte impacto en las prácticas y proyectos de los BP.

Esto nos lleva a la segunda dimensión, la de los BP como prácticas político-pedagógicas alternativas a las hegemónicas y que propugnan un cambio social radical. En la medida en que piensan y practican otro tipo de educación (Chalela y Charaf, 2017), entra en juego en esta dimensión qué tipo de construcción social promueven los BP, en qué sujeto educativo están pensando, qué proyecto emancipatorio están proponiendo (Garelli, Cordero, Mengascini y Dumrauf, 2019).

La desnaturalización de ciertas prácticas es un rasgo común dentro de estos espacios (Lázaro, Alfieri y Santana, 2019), por eso decimos que los BP, como parte de diversos movimientos sociales, conforman una nueva forma societal, política y cultural anclada en el territorio y con una perspectiva emancipatoria a largo plazo. Estas experiencias habilitan una dimensión disruptiva - y a su vez creativa - de los movimientos sociales, que se mantiene en el espacio-tiempo a partir de la recreación de prácticas y discursos que van "más allá" de la política institucional, con una temporalidad que trasciende las acciones colectivas de protesta focalizadas en el momento de visibilidad en el espacio público y que conforman "campos de experimentación educativos" en constante cambio y tensión con las prácticas bancarias de la educación hegemónica, incluso dentro de las mismas experiencias (Aguiló y Wahren, 2014; Janjetic, 2019; Alfieri y Lázaro, 2019b).

"Nosotros apostamos y pensamos a la multiplicación de los BP como experiencias contrahegemónicas de educación popular desde las organizaciones sociales, como espacios de construcción de poder popular, como experiencias educativas prefigurativas de esa educación distinta que queremos para nuestra sociedad, apostamos a que ese tipo de educación 
se multiplique." (Francisca, educadora BP Villa Soldati, MPLD-RBPC, GEMSEP, 2015).

Comprendemos, entonces, a los BP como prácticas político-pedagógicas emergentes de una nueva sociedad que se construye desde lo educativo anclado en los territorios. En este sentido, los BP implican verdaderos "campos de experimentación social" de los que habla el sociólogo portugués Boaventura de Sousa Santos (2003), desde los cuales los movimientos sociales impulsan formas educativas alternativas y en disputa con las lógicas hegemónicas de lo escolar (tanto de la gestión estatal como de la privada), a la vez que fortalecen los proyectos emancipatorios que estos movimientos sociales proponen desde sus territorios específicos —entendidos como "territorios insurgentes" (Aguiló y Wahren, 2014)—, donde los movimientos sociales logran desplegar sus diferentes propuestas alternativas a la forma societal hegemónica.

\section{Reflexiones finales}

Los BP surgen como una forma de desarrollo político a partir de una lectura de la estructura de oportunidades políticas que ofrecía la configuración social y estatal de una coyuntura determinada (Tarrow, 2009). Si bien no ha habido un motivo unívoco, sostenemos que existe una matriz común en la mayoría de las organizaciones populares que desarrollaron bachilleratos, que refiere a una forma de dar cuenta de la ausencia de políticas de educación de adultos desde el Estado, luego del vaciamiento neoliberal cristalizado durante la década del noventa.

A la vez, podemos afirmar que los BP aparecen como una experiencia novedosa de intervención de diferentes movimientos sociales que confluyen a través de una experiencia educativa que convive con espacios institucionales pero disruptivos, en una permanente tensión entre la autonomía y la heteronomía. Enmarcadas en el contexto de surgimiento de las rebeliones de 2001, lograron recrearse como experiencias alternativas ancladas en territorios diversos y propulsadas por una diversidad de organizaciones sociales que - si bien han mantenido diferencias y tensiones (incluyendo escisiones y reagrupamientos de sus articulaciones) - han mantenido importantes espacios de articulación y referencialidad hacia el espacio público en general y hacia el campo educativo en particular, lo que resulta un caso inédito en las propuestas pedagógicas y educativas de los movimientos sociales de Argentina y América Latina.

En este sentido, pese a los cambios de signo político de los sucesivos gobiernos, mantuvieron su autonomía y se reinventaron de acuerdo con las cambiantes coyunturas políticas, incluso durante el período macrista (20152019), cuando empeoraron drásticamente las condiciones socioeconómicas 
de las poblaciones que habitaban los BP y sus territorios adyacentes; fueron y son espacios de contención y reafiliación social, anclados territorialmente y que abarcan diferentes esferas de la vida de quienes transitan y construyen estas experiencias cotidianamente.

Asimismo, cabe resaltar que los BP no son escuelas con un formato que se encuentre suturado y donde se pueda hallar una lógica homogénea y continuada en el tiempo en las diferentes experiencias, por el contrario, son experiencias que "están siendo", que se construyen diariamente por el proceso dialéctico de discusión y praxis que permiten reinventar, modificar, ampliar y reforzar la experiencia entre educandos y educadores. Cada BP, con sus particularidades, expresa un proceso único que continúa (re)creando los procesos pedagógicos de su propuesta. Lejos de remitirse a ofrecer solamente una solución concreta a los problemas educativos de la población de jóvenes y adultos, los BP tienen la perspectiva de "una escuela nueva para un mundo nuevo", y en estos procesos el hecho de ser parte de movimientos sociales más amplios les aporta una perspectiva emancipatoria enraizada en "territorios insurgentes" practicados y habitados por los propios sujetos educativos.

\section{Referencias bibliográficas}

Aguiló, V. y J. Wahren (2014). Los bachilleratos populares de Argentina como “campos de experimentación social”. Argumentos, 27(74), pp. 97-114.

Alcántara, M. (2016). Investigación universitaria y sectores populares: Un estudio de caso en torno a las experiencias de bachilleratos populares. Ponencia presentada en las IX Jornadas de Sociología de la Universidad Nacional de La Plata, La Plata.

Alfieri, E. y F. Lázaro (2019a). Educación popular desde los bordes. Mirada(s) desde el bachillerato popular Maderera Córdoba. Buenos Aires: CEIPHAcercándonos Ediciones.

Alfieri, E. y F. Lázaro (2019b). Lo político pedagógico: Los bachilleratos populares en Argentina. Revista Cocar, 13(27), pp. 4-19.

Ampudia, M. y R. Elisalde (2015). Bachilleratos populares en la Argentina: Movimiento pedagógico, cartografía social y educación popular. Polifonías Revista de Educación, IV(7), pp. 154-177.

Blaustein Kappelmacher, A. L.; P. Rubinsztain y S. Said (2018). Las disputas por los sentidos de la educación. Los bachilleratos populares en el ciclo kirchnerista en la Argentina. En CLACSO (2018). Las disputas por lo público en América Latina y el Caribe. Buenos Aires: CLACSO, pp. 125-158. 
Brickman, D.; M. Chirom y J. Wahren (2012). Acciones colectivas y articulación política-pedagógica de los movimientos sociales: El caso de la Coordinadora de Bachilleratos Populares (2003-2012). Ponencia presentada en las III Jornadas Internacionales de Problemas Latinoamericanos, Mendoza.

Carnelli, L. y J. Furfaro (2015). Entre la autonomía y el reconocimiento: Las complejas relaciones entre los bachilleratos populares y el Estado en el caso de la Ciudad de Buenos Aires (2008-2014). Ponencia presentada en las XI Jornadas de Sociología, Buenos Aires.

Castoriadis, C. (2010). La institución imaginaria de la sociedad. Buenos Aires: Tusquets.

CEIP Histórica (2016). Praxis politica y educación popular. Apuntes en torno a una pedagogía emancipatoria en las aulas del Bachillerato IMPA. Buenos Aires: Naranjo en Flor-Editorial Rioplatense.

Chalela, A. y S. Charaf (2017). En búsqueda de una didáctica de la educación popular: bachillerato popular de jóvenes y adultos IMPA (CEIP Histórica). El Toldo de Astier, 8(14), pp. 121-125.

Chiaradia, E. y M. Favre (2019). El derecho a la educación por propia mano. ¿Una educación pública no estatal? Ponencia presentada en las XIII Jornadas de Sociología, Buenos Aires.

De Sousa Santos, B. (2003). Crítica de la razón indolente: Contra el desperdicio de la experiencia: para un nuevo sentido común: la ciencia, el derecho y la política en la transición paradigmática. Bilbao: Desclée de Brouwer.

Freire, P. (1985). Pedagogía del oprimido. Madrid: Siglo XXI.

García, J. (2018). La producción cultural del sujeto crítico: Construcciones de conocimientos en "bachilleratos populares" [Tesis de doctorado]. Facultad de Filosofía y Letras, Universidad de Buenos Aires.

Garelli, F.; S. Cordero; A. Mengascini y A. Dumrauf (2019). Caminos para la educación en salud desde la educación popular: Experiencias en bachilleratos populares de Argentina. Ciência \& Educação (Bauru), 25(1), pp. 5-24.

GEMSEP (2014). Educación de jóvenes y adultos bajo la gestión kirchnerista: Aportes para un análisis crítico del Programa FinEs 2. Revista Encuentro de Saberes, 4, pp. 60-68. 
GEMSEP (2015). 10 años de bachilleratos populares en Argentina. Debates de las coordinadoras: Coordinadora de bachilleratos populares en Lucha, Red de bachilleratos populares Comunitarios y Batalla Educativa. Buenos Aires: GEMSEP. Disponible en: <https://drive.google.com/file/ d/0B9WAEryqfqZ5WVZYX2FaNX1QVzg/view> [acceso 22 de agosto de 2016].

GEMSEP (2016). Relevamiento Nacional de Bachilleratos Populares de Jóvenes y Adultos. Buenos Aires: GEMSEP. Disponible en: <https://drive.google. com/file/d/0B9WAEryqfqZ5MUd4OHRQM2NPMFk/view $>$ [acceso $10 \mathrm{de}$ abril de 2017].

Gluz, N.; A. Burgos y M. Karolinski (2008). Movimientos sociales, educación popular y escolarización "oficial”: La autonomía "en cuestión”. Ponencia presentada en las I Jornadas Internacionales de problemas Latinoamericanos, Mar del Plata.

Grossi, P. y S. Bergalio (2019). Discusiones respecto al salario docente y vida cotidiana en los bachilleratos: Los casos de los bachilleratos populares Salvador Herrera e IMPA. Ponencia presentada en las XIII Jornadas de Sociología, Buenos Aires.

Janjetic, M. B. (2019). Los bachilleratos populares como alternativas pedagógicas: Una mirada desde sus estudiantes. Ponencia presentada en el Primer Congreso Internacional de Ciencias Humanas - Humanidades entre pasado y futuro. Escuela de Humanidades, Universidad Nacional de San Martín, San Martín.

Lázaro, F.; E. Alfieri y F. Santana (2019). Educaciones populares y pedagogías críticas. Buenos Aires: Editorial El Colectivo.

Longa, F.; F. Stratta y J. Wahren (2014). Debates en y desde los bachilleratos populares: Estado, sindicatos y pedagogías populares. Ponencia presentada en las IV Jornadas Internacionales de Problemas Latinoamericanos América Latina, Foz do Iguaçú.

López Fittipaldi, M. (2016). Movimientos sociales, jóvenes y educación. Los "bachilleratos populares" como experiencias socioeducativas emergentes en contextos de desigualdad social. Ponencia presentada en las Jornadas Nacionales y III Latinoamericanas de Investigadores/as en Formación en Ciencias de la Educación, Buenos Aires. 
Melucci, A. (1994). ¿Qué hay de nuevo en los 'nuevos movimientos sociales'? Los nuevos movimientos sociales. De la ideología a la identidad. Madrid: Centro de Investigaciones Sociológicas (CIS).

Odriozola, J. (2015). Bachilleratos populares: Una batalla de trabajadorxs de la educación desde los movimientos sociales. Una lucha de largo aliento $y$ de largo alcance. Ponencia presentada en las XI Jornadas de Sociología.

Pagano, A. (2019). Organizaciones sociales y experiencias educativas en el conurbano bonaerense. Concepciones y estrategias populares para enfrentar la desigualdad. Ponencia presentada en las XIII Jornadas de Sociología.

Palomeque, M. (2018). Los desafios de los bachilleratos populares oficializados: El caso del bachillerato popular Carlos Fuentealba de Luján [Tesis de doctorado]. Universidad Nacional de Luján.

Svampa, M. (2008). Cambio de época. Movimientos sociales y poder político. Madrid: Siglo XXI.

Tarrow, S. (2009). El poder en movimiento. Los movimientos sociales, la acción colectiva y la poltica. Madrid: Alianza Editorial.

Torres Carrillo, A. (2017). Prácticas educativas en movimientos sociales de América Latina. Folios, 46, pp. 3-14.

Zibechi, R. (2003). Genealogía de la revuelta. Argentina: La sociedad en movimiento. La Plata-Montevideo: Letra Libre-Nordan Comunidad.

Zibechi, R. (2005). La educación en los movimientos sociales. Programa de las Américas. Silver City, NM: International Relations Center. Disponible en: $\quad<$ http://bibliotecadigital.conevyt.org.mx/colecciones/documentos/ Catedra_Andres_Bello/Agosto\%202007/Lecturas/Zibechi.pdf> [acceso 10 de octubre de 2015]

\section{Contribución de autoría}

El trabajo en su totalidad fue realizado por Juan Wahren. 